\title{
ANALISIS BISNIS MODEL CANVAS PADA OPERATOR JASA ONLINE RIDE-SHARING NOOMPANG
}

\author{
Yuniati Fransisca $^{1}$, Nidya Novalia ${ }^{2}$, Amalia Darawati ${ }^{3}$ \\ Program Studi Manajemen, Fakultas Ekonomi, Universitas Nurtanio, \\ Bandung1,2,3 \\ Email: alephtav314@gmail.com ${ }^{1}$, nidyanovalia@gmail.com², \\ amaliadrr@gmail.com ${ }^{3}$
}

\begin{abstract}
Innovation in the transportation sector with the principle of sharing economy has created a new service industry sector, namely online ride-sharing services. Companies can display in a simple but comprehensive manner the nine essential components of a business. A business model is a method that helps companies tell stories about the internal conditions of the company. This study aims to analyze the business model of Noompang using the Business Model Canvas analysis. This research uses descriptive-exploratory method. Data collection using the ghost interview method to the selected driver. Data obtained from interviews with partners, both drivers and passengers Noompang in Bandung - Jakarta and the results of studies of supporting literature. The results obtained from this study are that Noompang benefits from profit sharing with partner companies, profit sharing with driver partners, benefits from the Ovo e-wallet, and benefits from Google / Apple on application downloads.
\end{abstract}

Keywords: business model canvas, ride-sharing online services, noompang.

\begin{abstract}
Abstrak
Inovasi di bidang transportasi dengan prinsip ekonomi berbagi telah melahirkan sektor industri jasa baru yaitu jasa ride sharing online. Perusahaan dapat menampilkan secara sederhana namun komprehensif sembilan komponen penting dari sebuah bisnis. Model bisnis adalah metode yang membantu perusahaan bercerita tentang kondisi internal perusahaan. Penelitian ini bertujuan untuk menganalisis model bisnis Noompang dengan menggunakan analisis Business
\end{abstract}


Model Canvas. Penelitian ini menggunakan metode deskriptif-eksploratif. Pengumpulan data menggunakan metode wawancara hantu kepada pengemudi terpilih. Data diperoleh dari wawancara dengan rekanan, baik pengemudi maupun penumpang Noompang di Bandung - Jakarta serta hasil studi literatur pendukung. Hasil yang diperoleh dari penelitian ini adalah Noompang mendapatkan keuntungan dari pembagian keuntungan dengan perusahaan mitra, bagi hasil dengan mitra pengemudi, keuntungan dari Ovo e-wallet, dan manfaat dari Google/Apple pada pengunduhan aplikasi.

Kata Kunci: model bisnis canvas, ride-sharing, jasa transportasi online.

\section{PENDAHULUAN}

Inovasi teknologi telah bermunculan di beberapa sektor, tidak terkecuali pada sektor transportasi umum. Salah satu inovasi dalam bidang bisnis transportasi yaitu munculnya bisnis operator layanan transportasi online yang dikenal dengan istilah ride-sharing. Ride-sharing atau lebih dikenal dengan istilah bahasa Indonesia "numpang" merupakan bagian dari sistem sharing economy atau ekonomi berbagi yang berbasis teknologi pada industri jasa transportasi. Sistem sharing economy memungkinkan terjadinya sewa menyewa aset yang dimiliki, termasuk dalam hal ini meminjamkan tenaga dan kendaraan dalam wujud jasa online ride-sharing. Kendaraan yang biasa digunakan untuk bisnis ride-sharing terdiri dari kendaraan bermotor roda dua dan roda empat. Perpaduan konsep ridesharing yang dilengkapi dengan teknologi real time ini sangat menarik sehingga tidak jarang membuat banyak konsumen yang mencoba dan menjadi pelanggan layanan ini.

Keberadaan layanan ride sharing bukanlah hal baru di Indonesia. Namun untuk memastikan agar layanan transportasi tersebut bisa menjangkau kepercayaan konsumen, diperlukan sebuah sistem kerja yang bisa memastikan keselamatan penumpang dan pemberi tumpangan yang belum mengenal satu sama lain. Konsep layanan Noompang berawal dari munculnya ide untuk menyediakan jasa layanan pulang-pergi jarak dekat dengan harga yang terjangkau. Layanan jasa ini memungkinkan satu kendaraan diisi oleh beberapa konsumen dengan tujuan yang sama atau searah dengan tujuan utama sehingga dengan demikian biaya perjalanan pun bisa lebih terjangkau. Dengan berbagi perjalanan di Noompang, masyarakat dapat meningkatkan efisiensi transportasi jalan, menghemat uang perjalanan, dan mengurangi kepadatan lalu lintas. Guna memfasilitasi perjalanan dari titik A ke titik $\mathrm{B}$, penyedia tumpangan bisa mengatur jadwal perjalanan, titik keberangkatan dan tujuan, serta berapa banyak jumlah kursi yang tersedia di dalamnya.

Bisnis Dan Iptek | Sekolah Tinggi Ilmu Ekonomi Pasundan Bandung 
Model Bisnis menjelaskan alasan bagaimana organisasi menciptakan, memberikan, dan menangkap nilai (Osterwalder \& Pigneur, 2010). Usaha Kecil dapat memanfaatkan kanvas model bisnis sebagai salah satu strategi dalam menghadapi persaingan. Kanvas model bisnis khusus ini menggambarkan hubungan antara pemilik bisnis dan mitra mereka serta pelanggan mereka. Dalam kanvas model bisnis ini terdapat sembilan blok yang saling terkait satu sama lain: (1). Customer Segment, (2). Value Proposition, (3). Channel, (4). Customer Relationship, (5). Revenue Stream, (6). Key Resources, (7). Key Activities, (8). Key Partnership, (9). Cost structure. BMC merupakan sebuah alat dalam strategi manajemen untuk menerjemahkan konsep, konsumen, infrastruktur maupun keuangan perusahaan dalam bentuk elemen-elemen visual. Konsep bisnis model kanvas mengandalkan gambar - gambar ide sehingga setiap orang memiliki pemahaman yang sama dan nyata terhadap tipe-tipe konsumen, pengeluaran biaya, cara kerja perusahaan dan sebagainya.

Rumusan masalah pada penelitian ini adalah bagaimana gambaran model bisnis Noompang saat ini jika ditinjau dari aspek-aspek pada business model canvas dan bagaimanakah strategi pengembangan bisnis yang sesuai pada Noompang dengan menggunakan pendekatan business model canvas.

\section{LITERATURE REVIEW}

Menurut Osterwalder dan Pigneur (2015), Business Model Canvas (BMC) adalah salah satu alat strategi yang digunakan untuk mendeksripsikan sebuah mode bisnis dan menggambarkan dasar pemikiran tentang bagaimana organisasi menciptakan, memberi, dan menangkap nilai. Business Model Generation atau lebih populer dengan sebutan Business Model Canvas adalah satu alat untuk membantu kita melihat lebih akurat rupa usaha yang sedang atau akan dijalankan.

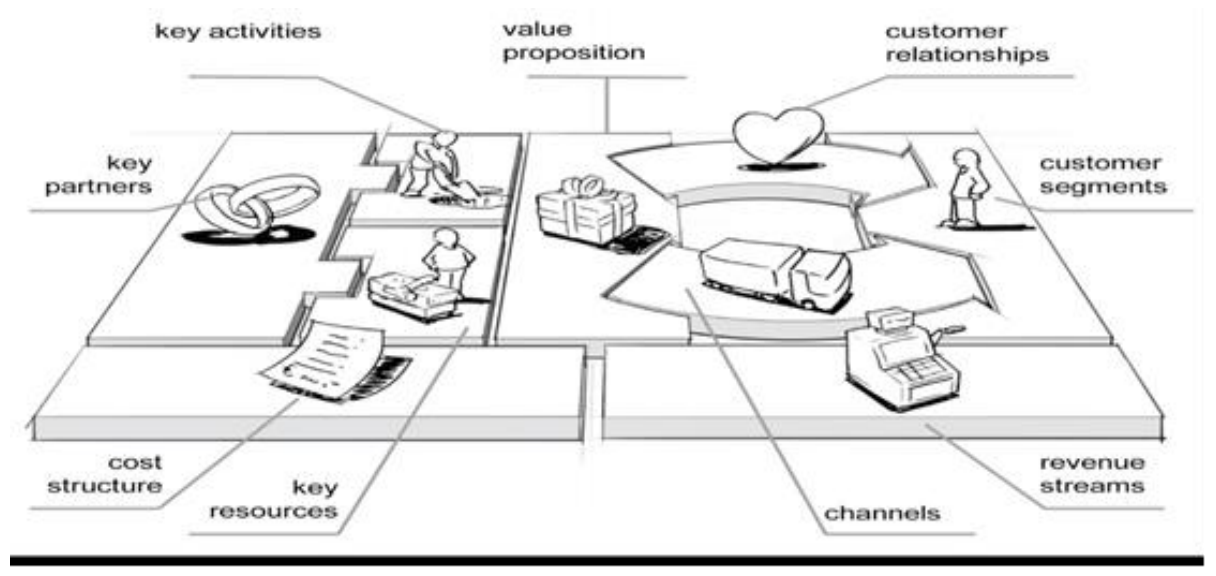

Bisnis Dan Iptek | Sekolah Tinggi Ilmu Ekonomi Pasundan Bandung 


$$
\text { April , } 2021
$$

\section{Gambar 1. Desain Business Model Canvas \\ Sumber : Os terwalder \& Pigneur (2015 : 19)}

Mengubah konsep bisnis yang rumit menjadi sederhana yang ditampilkan pada satu lembar kanvas berisi rencana bisnis dengan sembilan elemen kunci yang terintegrasi dengan baik didalamnya mencakup analisis strategi secara internal maupun eksternal (Osterwalder \& Pigneur, 2015). Business Model Canvas digambarkan melalui sembilan blok bangunan dasar yang menunjukkan logika bagaimana perusahaan bermaksud untuk menghasilkan uang. Sembilan blok ini mencakup empat bidang utama bisnis yaitu pelanggan, penawaran, infrastrukt ur, dan kelayakan keuangan.

Kesembilan blok bangunan dasar yang digunakan untuk penggambaran Business Model Canvas yaitu:

\section{Customer Segment (Segmen Pelanggan)}

Menurut Osterwalder dan Pigneur (2015 : 20), blok bangunan segmen pelanggan menggambarkan sekelompak orang atau organisasi berbeda yang ingin dijangkau atau dilayani oleh perusahaan. Pelanggan adalah inti dari setiap model bisnis. Tanpa pelanggan (yang memberikan keuntungan), tidak ada satupun perusahaan yang dapat bertahan dalam jangka waktu yang lama. Dalam rangka memenuhi kepuasan pelanggan, perusahaan mengelompokkan pelanggan ke dalam beberapa segmen yang berbeda berdasarkan kesamaan kebutuhan, kesamaan perilaku, dan lain-lain. Model bisnis dapat diterapkan dalam berbagai perusahaan baik kecil maupun besar. Suatu kelompok pelanggan dapat disebut sebagai segmen pasar apabila memerlukan pelayanan (value propositions) yang tersendiri arena permasahan dan kebutuhan secara khusus, dicapai dan dilayani dengan saluran distribusi (channels) yang berbeda; perlu pendekatan (customer relationship) yang berbeda; memberikan profitabilitas yang berbeda; dan memiliki kemampuan membayar yang berbeda sesuai dengan persepsi terhadap nilai yang mereka terima.

\section{Value Propositions (Proporsi Nilai)}

Blok bangunan proporsi nilai menggambarkan gabungan antara produk dan layanan yang menciptakan nilai untuk segmen pelanggan spesifik. Menurut Kotler (2017) dasar pemikiran yang diharapkan oleh pelanggan yaitu bagaimana mereka membeli suatu barang atau jasa di sebuah perusahaan, dengan mendapatkan nilai kepuasan tertinggi. Osterwalder dan Pigneur (2014) menyatakan value propositions adalah alasan yang membuat pelanggan beralih dari satu perusahaan ke perusahaan lain. Value propositions dapat memecahkan masalah pelanggan atau memuaskan kebutuhan pelanggan. Setiap value propositions terdiri dari gabungan produk atau jasa tertentu yang melayani 
kebutuhan segmen pelanggan spesifik yang manfaatnya dapat ditawarkan perusahaan kepada pelanggan. (Carter \& Carter, 2020)

\section{Channels (Saluran)}

Blok bangunan channels menggambarkan bagaimana sebuah perusahaan berkomunikasi dengan segmen pelanggannya dan menjangkau mereka untuk memberikan proporsi nilai. Saluran komunikasi, distribusi dan penjualan merupakan penghubung antara perusahaan dan pelanggan. Saluran adalah titik sentuh pelanggan yang sangat berperan dalam setiap kejadian yang mereka alami. Sebagian besar perusahaan menggunakan perantara atau saluran distribusi untuk menyalurkan produk mereka ke pasar. (Verrue, 2014)

\section{Customers Relationships (Hubungan Pelanggan)}

Customer relationships adalah tipe hubungan yang ingin dijalin dengan para pelanggan dari segmen pasar yang spesifik. Perusahaan seharusnya memikirkan tipe hubungan yang akan dijalin dengan para pelanggan dari berbagai segmen. Ada beberapa kategori dari customer's relationships yang dapat dipadukan dengan customer segments, antara lain:

1. Personal Assistance (Bantuan Personal), yang didapatkan berdasarkan interaksi antar individu. Pelanggan dapat berkomunikasi dengan wakil dari perusahaan secara langsung selama proses pembelian ataupun pasca pembelian. Hal ini sering dilakukan melaui call center, email, maupun media lainnya.

2.Dedicated Personal Assistance (Bantuan Personal yang Khusus), dalam hal ini perusahaan memberi perlakuan istimewa kepada pelanggan sebagai pribadi khusus. Biasanya perusahaan menunjuk seorang wakil untuk pelanggan tertentu.

3. Self-service (Swalayan), dalam tipe hubungan ini, perusahaan tidak melakukan interaksi langsung atau personal terhadap para pelanggan. Perusahaan menyediakan hal-hal yang penting untuk membantu pelanggan memenuhi kebutuhannya.

4. Automated Service (Layanan Otomatis), merupakan jenis hubungan personal assistance dengan self service.

5. Communities (Komunitas), umumnya digunakan oleh perusahaan sering untuk lebih mendekatkan dengan pelanggan dan memfasilitasi pelanggan yang menjadi anggota komunitas.

6. Co-creation, kebanyakan perusahaan kembali pada hubungan perusahaan pelangga $\mathrm{n}$ secara tradisional untuk memberikan nilai tambah. Dalam jenis hubungan ini, perusahaan melibatkan pelanggan untuk menciptakan nilai bagi pelanggan itu sendiri. 


\section{Revenue Streams (Arus Pendapatan)}

Revenue streams adalah pendapatan yang diterima perusahaan dari masingmasing segmen pasar atau dengan kata lain revenue streams adalah pemasukan yang biasanya diukur dalam bentuk uang yang diterima perusahaan dari pelangganya. (Keane, Cormican \& Sheahan, 2018). Jika kepuasan pelanggan adalah jantung dari sebuah model bisnis, maka revenue streams adalah pembuluh arterinya.

\section{Key Resources (Sumber Daya Utama)}

Key resources menggambarkan aset-aset terpenting yang diperlukan agar sebuah model bisnis dapat berfungsi. Setiap model bisnis memerlukan sumber daya utama. Sumber daya utama ini membuat perusahaan membentuk dan menawarkan value propositions, mendapatkan pasar, mengawasi hubungan dengan segmensegmen pasar, dan mendapatkan penghasilan. (Kühne \& Böhmann, 2018) Key resources dapat berupa benda fisik, finansial, intelektual, maupun manusia.

\section{Key Activities (aktivitas kunci)}

Key activities adalah tindakan-tindakan terpenting yang harus diambil perusahaan agar dapat beroperasi dengan sukses (Osterwalder \& Pigneur, 2014). Setiap model bisnis memiliki aktivitas-aktivitas kunci juga diperlukan untuk menciptakan dan memberikan proposi nilai, menjangkau pasar, mempertahankan hubungan pelanggan, dan memperoleh pendapatan.

\section{Key Partnership (Kemitraan Utama)}

Key partnership adalah mitra utama dalam bisnis, misalnya supplier, sehingga model bisnis dapat berjalan. (Carvalho, Galina \& Sánchez-Hernández, 2020) Perusahaan menjalin kerjasama menjadi landasan dari beberapa model bisnis. Perusahaan membuat aliansi mengoptimasi model bisnisnya, mengurangi risiko, atau memperoleh sumber daya.

\section{Cost Structure (Struktur Biaya)}

Cost structure adalah komponen-komponen biaya yang digunakan supaya organisasi atau perusahaan bisa berjalan sesuai model bisnisnya. Membuat dan meningkatan nilai tambah, berhubungan dengan pelanggan, dan mendapatkan penghasilan semuanya. (Alt \& Zimmermann, 2014)

\section{METODE PENELITIAN}

Jenis penelitian yang digunakan adalah penelitian deskriptif kualitatif, di mana desain penelitian yang disusun dalam rangka memberikan gambaran secara 
sistematis tentang informasi ilmiah yang berasal dari subjek atau objek penelitian. Sugiyono (2017) mengatakan bahwa metode penelitian kualitatif adalah metode penelitian yang berlandaskan pada filsafat positivisme, digunakan untuk meneliti pada kondisi obyek yang alamiah (sebagai lawannya adalah eksperimen), dimana peneliti adalah sebagai instrumen kunci pengambilan data dilakukan dengan teknik pengumpulan dengan triangulasi (gabungan).

Analisis data bersifat induktif/kualitatif, dan hasil penelitian kualitatif lebih menekankan makna daripada generalisasi. Pengumpulan data menggunakan metode wawancara terhadap mitra pengemudi maupun penumpang Noompang, observasi, dan analisis dokumen dan literatur pendukung. Teknik penentuan informan yang dilakukan oleh peneliti dalam penelitian ini adalah teknik purposive sampling. Menurut Sugiyono (2017), teknik purposive sampling adalah teknik pengambilan sampel sumber data dengan pertimbangan tertentu.

Pemilihan informan sebagai sumber data dalam penelitian ini adalah berdasarkan pada asas subyek yang menguasai permasalahan, memiliki data, dan bersedia memberikan informasi lengkap dan akurat. Pihak yang menjadi informan pada penelitian ini berjumlah enam orang yang terdiri dari satu orang CEO sekaligus Co-Founder Noompang Indonesia, satu orang CMO Noompang Indonesia, satu orang Product Manager, satu orang dari divisi Digital Marketing, satu orang pengemudi Noompang Indonesia, dan satu orang penumpang Noompang Indonesia rute Bandung-Jakarta.

\section{HASIL DAN PEMBAHASAN}

Noompang sebagai salah satu platform aplikasi online ride- telah menerapkan Business Model Canvas dalam usahanya. Customer Segment dari Noompang adalah orang dewasa dengan rentang usia 18 hingga 45 tahun. Value Propositions dari aplikasi Noompang adalah sharing economy dengan berbagi kursi kosong terasa betul manfaatnya, mulai dari biaya yang lebih terjangkau karena adanya sharing, mengurangi kemacetan karena mengurangi kendaraan jika tujuannya sama, dan mempunyai teman jalan pada saat berkendara yang memunculkan komunitas baru.

Cara yang digunakan oleh Noompang untuk berkomunikasi dengan segmennya adalah melalui media sosial seperti Whatsapp, Line, Twitter, Instagram, dan Youtube. Tim Noompang melakukan interaksi dengan para konsumen melalui media online dan mengadakan gathering untuk komunitas yang tumbuh bersama Noompang, membuat promo serta membuat email dan whatssapp newslatter tentang perkembangan Noompang. Blok bangunan. Arus pendapatan 
menggambarkan pendapatan yang dihasilkan oleh perusahaan dari masing masing segmen pelanggan, bahwa biaya harus mengurangi pendapatan untuk menghasilkan pemasukan (Osterwalder \& Pigneur, 2014). Seluruh pendapatan Noompang berasal dari penggunaan aplikasi, serta biaya jasa perjalanan mitra dengan konsumen yang dibayarkan pengguna melalui dompet elektronik OVO.

Blok bangunan key resources Noompang karyawan itu sendiri atau Skilled Staff, gedung kantor tempat beroperasinya kegiatan bisnis Noompang, Google Maps, aplikasi Noompang, dan infrastruktur server. Aktivitas kunci dari yaitu menghubungkan driver dengan penumpang serta melakukan manajemen big data. Noompang menjalin hubungan kemitraan dengan para investor untuk pengembangan perusahaan yang terdiri dari mitra pengemudi, mitra penjual makanan, Apps store ios for iphone, Google store for android, Ovo for payment method, pemasok atribut seperti baju dan jaket Noompang serta dengan penyedia infrastruktur server. Struktur biaya Noompang adalah biaya untuk mitra pengemudi dan penjual makanan, penyewaan infrastruktur server, biaya API Google maps dan ios, gaji pegawai kantor, biaya listrik dan wifi, serta biaya pemeliharaan dan perbaikan sistem.

Dari penjelasan diatas, maka dapat disimpulkan Business Model Canvas Noompang saat ini dapat digambarkan sebagai berikut:

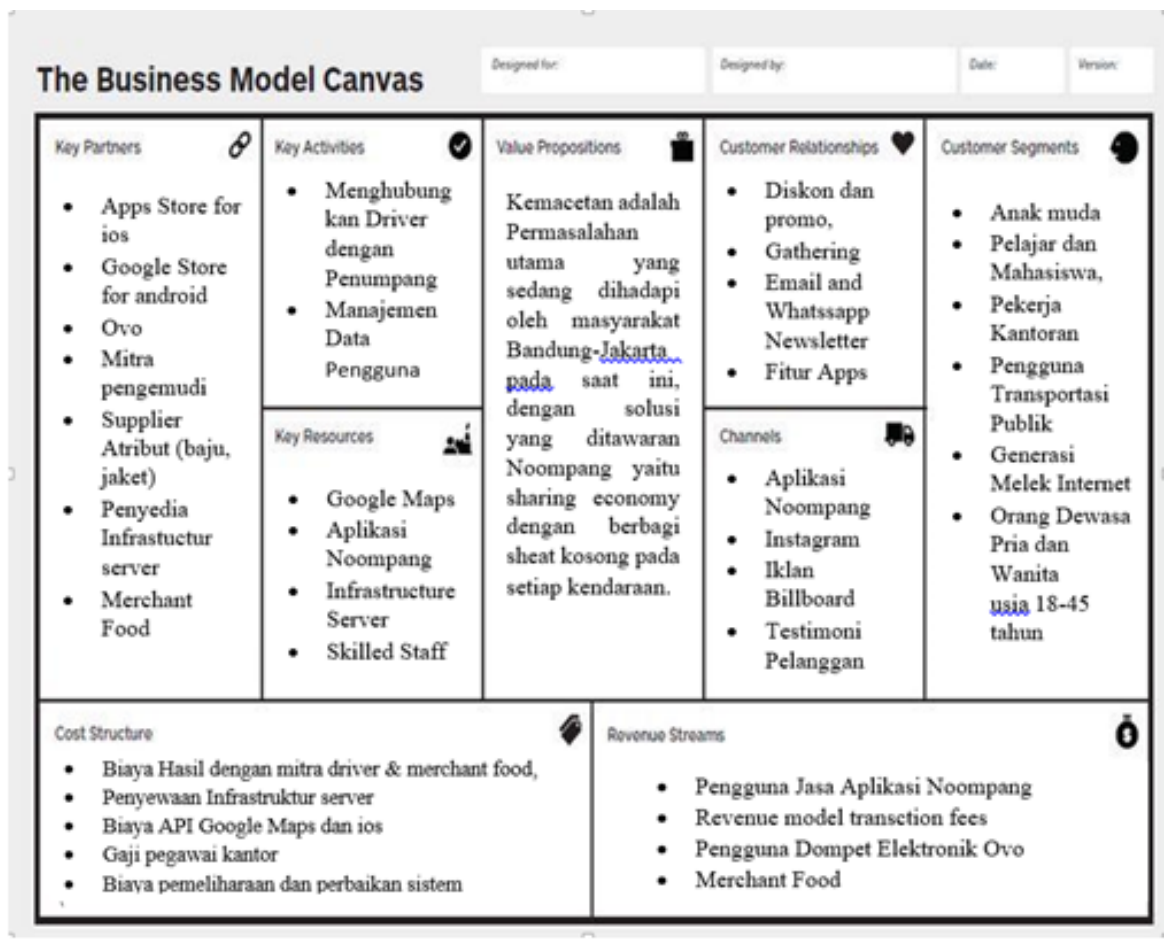

Gambar 2. Business Model Canvas Noompang Saat Ini 
Model bisnis platform online ride sharing Noompang sudah sesuai dengan standar business model canvas dari Osterwalder dan Pigneur yang terdiri dari sembilan blok yang saling berkaitan satu sama lain. Dari hasil analisa, peneliti merekomendasikan adanya penambahan strategi bisnis pada 4 blok yaitu Channels, Customer Relationship, Key Partnership dan Revemue Streams. Walaupun Noompang sudah menerapkan sistem e-bussines dalam proses marketingnya, namun kegiatan pemasaran juga perlu dilakukan media elektronik seperti televisi dan radio. Noompang juga disarankan melakukan pemsaran melalui youtube yang otomatis akan langsung masuk ke website Noompang. Customer service call via telepon juga perlu disediakan dengan pelanggan untuk memudahkan komunikasi penyedia jasa, mitra, dan pengguna jasa. Pada blok customer relationship, disarankan Noompang memberikan promo yang labih menarik seperti diskon berdasarkan event tertentu dan memberikan gift/souvenir bagi pelanggan yang sudah melakukan repeat buying serta pemberian giveaway melalui sosial media. Pada blok key partnership, peningkatan layanan delivery antar kota juga dapat ditingkatkan dengan melalui strategi harga seperti pemberian harga khusus atau gift. Pada blok revenue streams, penambahan system pembayaran melalui kartu kedit dan debit perlu ditambahkan untuk semakin mempermudah transaksi bisnis.

\begin{tabular}{|c|c|c|c|c|}
\hline $\begin{array}{l}\text { KeV Partners } \\
\text { - Apps Store for } \\
\text { ios } \\
\text { - Google Store } \\
\text { for android } \\
\text { - Ovo } \\
\text { - Mitra } \\
\text { pengemudi } \\
\text { - Supplier } \\
\text { Atribut (baju, } \\
\text { jaket) } \\
\text { - Penyedia } \\
\text { Infrastuctur } \\
\text { server } \\
\text { - Merchant } \\
\text { Food } \\
\text { - Memperluas } \\
\text { mitra } \\
\text { merchant } \\
\text { delivery food } \\
\text { antar kota } \\
\text { - Penawaran } \\
\text { harga special } \\
\text { delitvery food } \\
\text { order. }\end{array}$ & $\begin{array}{l}\text { Key Resources } \\
\text { - Google Maps } \\
\text { - Aplikasi } \\
\text { Noompang } \\
\text { - Infrastructure } \\
\text { - Server } \\
\text { - Skilled Staff }\end{array}$ & $\begin{array}{l}\text { Value Proposition } \\
\text { Kemacetan adalah } \\
\text { Permasalahan } \\
\text { utama yang } \\
\text { sedang dihadapi } \\
\text { oleh masyarakat } \\
\text { Bandung-Jakartan } \\
\text { pada saat ini, } \\
\text { dengan solusi } \\
\text { yang ditawaran } \\
\text { Noompang yaitu } \\
\text { sharing economy } \\
\text { dengan berbagi } \\
\text { sheat kosong pada } \\
\text { setiap kendaraan. }\end{array}$ & $\begin{array}{l}\text { Customer } \\
\text { Relationships } \\
\text { - Diskon dan } \\
\text { promo, } \\
\text { - Gathering } \\
\text { - Email and } \\
\text { Whatssapp } \\
\text { Newsletter } \\
\text { - Fitur Apps } \\
\text { - Gift/ souvenir } \\
\\
\text { - Aplikasi } \\
\text { - Channels } \\
\text { Ioompang } \\
\text { Instagram } \\
\text { - Tlan Billboard } \\
\text { - Testimoni dan } \\
\text { review } \\
\text { Pelanggan } \\
\text { - Fitur customer } \\
\text { service } \\
\text { - Digital e- } \\
\text { Anveineer }\end{array}$ & $\begin{array}{l}\text { Customer } \\
\text { Segments } \\
\text { - Anak muda } \\
\text { - Pelajar dan } \\
\text { Mahasiswa, } \\
\text { - Pekerja } \\
\text { Kantoran } \\
\text { - Pengguna } \\
\text { Transportasi } \\
\text { Publik } \\
\text { - Generasi } \\
\text { Melek Internet } \\
\text { - Orang Dewasa } \\
\text { Pria dan } \\
\text { Wanita } \\
\text { usia 18-45 } \\
\text { tahun }\end{array}$ \\
\hline \multicolumn{5}{|l|}{$\begin{array}{l}\text { food, } \\
\text { - Benyewaan } \\
\text { - Biaya API C } \\
\text { - Gaji pegawa } \\
\text { - Biaya pemel }\end{array}$} \\
\hline
\end{tabular}

Gambar 3. Rekomendasi Business Model Canvas Noompang 
April , 2021

\section{KESIMPULAN}

Model bisnis platform online ride-sharing Noompang sudah sesuai dengan standar business model canvas dari Osterwalder dan Pigneur yang terdiri dari sembilan blok yang saling berkaitan satu sama lain.

Dari hasil analisa, peneliti merekomendasikan adanya penambahan strategi bisnis pada 4 blok yaitu Channels, Customer Relationship, Key Partnership dan Revemue Streams. Walaupun Noompang sudah menerapkan sistem e-bussines dalam proses marketingnya, namun kegiatan pemasaran juga perlu dilakukan media elektronik seperti televisi dan radio. Noompang juga disarankan melakukan pemsaran melalui youtube yang otomatis akan langsung masuk ke website Noompang. Customer service call via telepon juga perlu disediakan dengan pelanggan untuk memudahkan komunikasi penyedia jasa, mitra, dan pengguna jasa. Pada blok customer relationship, disarankan Noompang memberikan promo yang labih menarik seperti diskon berdasarkan event tertentu dan memberikan gift/souvenir bagi pelanggan yang sudah melakukan repeat buying serta pemberian giveaway melalui sosial media. Pada blok key partnership, peningkatan layanan pengantaran antar kota juga dapat ditingkatkan dengan melalui strategi harga seperti pemberian harga khusus atau gift. Pada blok revenue streams, penambahan sistem pembayaran melalui kartu kedit dan debit perlu ditambahkan untuk semakin mempermudah transaksi bisnis.

\section{REFERENSI}

Alt, R., \& Zimmermann, H. D. (2014). Status of business model and electronic market research: An interview with Alexander Osterwalder. Electronic Markets, 24(4), 243-249.

Carter, M., \& Carter, C. (2020). The Creative Business Model Canvas. Social Enterprise Journal, 16(2), 141-158. https://doi.org/10.1108/SEJ-03-20190018

Carvalho, L., Galina, S., \& Sánchez-Hernández, M. I. (2020). An international perspective of the business incubators' perception about business model canvas for startups. Thunderbird International Business Review, 62(5), 503-513. https://doi.org/10.1002/tie.22112

Keane, S. F., Cormican, K. T., \& Sheahan, J. N. (2018). Comparing how entrepreneurs and managers represent the elements of the business model canvas. Journal of Business Venturing Insights, 9, 65-74. https://doi.org/10.1016/j.jbvi.2018.02.004 
Kühne, B., \& Böhmann, T. (2018). Requirements for representing data-driven business models-Towards extending the business model canvas.

Osterwalder, A. \& Pigneur, Y. (2014). Business Model Generation. Cetakan ke-7. Jakarta: PT Elex Media Komputindo.

Sugiyono. 2017. Metode Penelitian Kualitatif. Cetakan ke-1. Bandung: Alfabeta.

Verrue, J. (2014). A critical investigation of the Osterwalder business model canvas: an in-depth case study. In Belgian Entrepreneurship Research Day. 